\title{
Integrated approach for sinkhole evaluation and evolution prediction in the Central Ebro Basin (NE Spain)
}

\author{
Óscar Pueyo Anchuela*, Andrés Pocoví Juan, Antonio M. Casas Sainz, \\ Javier Gracia Abadias, and Carlos L. Liesa Carrera \\ Grupo de Investigación Geotransfer, Instituto Universitario en Ciencias Ambientales Universidad de Zaragoza, Pedro Cerbuna, 12 , 50009 Zaragoza, Spain
}

\begin{abstract}
Evaluation of karst hazards benefits from the integration of different techniques, methodologies and approaches. Each one presents a different signature and is sensitive to certain indicators related to karst hazards. In some cases, detailed analysis permits the evaluation of representativeness either from isolated approaches or by means of integrated analyses. In this study, we present the evaluation of an area with high density of karstic collapses at different evolutionary stages through the integration of surficial, historical, geomorphological and geophysical data in order to finally define the evolutionary model for karst activity development. The obtained dataset permits to identify different steps in sinkhole evolution: (i) cavities and open sinkholes, (ii) filling of these cavities, with materials having different signatures, (iii) the progression from collapses to subsidence sinkholes and (iv) enlargement through collapses in marginal areas of previous sinkholes. The presence of different stages of this evolutionary model permits to determine their own signatures that can be of application in contexts where analysis cannot be so systematic and also to evaluate the definition of the marginal areas of previous sinkholes as the most hazardous sectors.
\end{abstract}

Keywords: $\quad$ karst, sinkhole, geophysics, sinkhole inventory, Ebro Basin

Received 28 September 2016; Revised 31 May 2017; Accepted 1 June 2017

Citation: Pueyo Anchuela Ó., Pocoví Juan A., Casas Sainz A.M., Gracia Abadías J. and Liesa Carrera H.D., 2017. Integrated approach for sinkhole evaluation and evolution prediction in the Central Ebro Basin (NE Spain). International Journal of Speleology, 46 (2), 237-249. Tampa, FL (USA) ISSN 0392-6672 https://doi.org/10.5038/1827-806X.46.2.2064

\section{INTRODUCTION}

The use of geomorphological analysis based on aerial photographs with stereoscopic coverage has been one of the most usual and useful approaches in the characterization of sinkholes and development of sinkhole inventories. Information for these inventories can be complemented by field inspection, records of infrastructures and building damages, inhabitant interviews and topographical analysis. All these data can permit the overall definition of the karst matter, its characterization and its historical recent evolution (e.g., Waltham et al., 2005; Cooper et al., 2011).

These datasets can allow to the exclusion of high susceptibility karstic zones in urban or infrastructure planning and also help in the evaluation of geological factors that favor karst sinkholes. This evaluation can also lead to understand the conditions that favor karst development in areas where historicalgeomorphological datasets are scarce or ambiguous, and to predict future unstable zones. These procedures can include heuristic, deterministic or statistical evaluations (e.g., Simón et al., 1991, Soriano \& Simón, 1995; Simón \& Soriano, 2002; Simón et al., 1998; Yilmaz, 2007; Lamelas et al., 2008; Galve et al., 2009a,b; Thierry et al., 2009; Perrin et al., 2015), and are often based on long records of sinkhole activity and the assumption that new subsidence foci are prone to develop in sectors where previous evidences exist. This generalization resides in the indirect evaluation of the geological, geomorphological, geotechnical, hydrogeological, etc. factors that favor the development of sinkhole clusters.

Geomorphological datasets or sinkhole inventories can be integrated by using satellite data (topography), LiDAR and InSAR technologies, in order to identify recent subsidence processes (e.g., Berardino et al., 2002; Lindsay \& Creed, 2006; Castañeda et al., 2009). These approaches can ultimately lead to the creation of inventories in more or less automatic manners (e.g., Wu et al., 2016; Zhou et al., 2016). Poor data accessibility, requirements of wide time-span intervals for the historical analysis or anthropogenic or natural modifications can limit the 
representativeness, completeness and accuracy of inventories (e.g., Galve et al., 2009; Al- Kouri et al., 2013; Gutiérrez et al., 2014).

In this sense, both geomorphological maps and sinkhole inventories can be the background for subsequent evaluation of susceptibility and definition of hazard maps that can improve the prediction availability. These approaches and the statistical regression of previous data allow the identification of karstic evidences and definition of their overall boundaries. However, they cannot be directly used to map voids prone to collapse (Norman \& Watson, 1975). Moreover, when karst processes involve very soluble rocks and high water availability, karst can evolve at very high rates, thus requiring the prediction and delimitation of susceptible areas or near-to-thesurface cavities for the definition of unstable sectors (Martinez et al., 1998; Walthan et al., 2005; Gutiérrez et al., 2008).

Geophysical approaches have also been used as another data source for sinkhole inventories, permitting to reduce uncertainties related to recent surficial anthropogenic or natural modifications, and also for the prediction of collapses without surface expression (Benson \& Yuhr, 1993; Pueyo Anchuela et al., 2011a; Kaufmann, 2014 and references therein). In many cases, geophysical results allow to define, with high resolution, the limits of pre-existing karstic evidences and their underground geometry. However, they are strongly dependent on the particular features associated with karst processes, such as sinkhole fillings, decompaction of underground materials, water table changes, more dense vegetation growth and/or structural and geometrical changes of the underground units affected by cavity propagation; see for example Pueyo Anchuela et al. (2016). The integrated evaluation using different geophysical techniques can allow to improve, having in mind a constrained geological evolutionary karst model, sinkhole predictive models (Pueyo Anchuela et al., 2010a, 2011b; Frumkin et al., 2011 and references therein).

In this work, a detailed analysis in a sector with recent and active karstic evidences has been performed. Geomorphological, field inspection and geophysical data were integrated in order to evaluate sensitivity of the different approaches to the definition and inventory of karst sinkholes. The proposal and evaluation of the sinkhole evolutionary model led to the improvement of sinkhole knowledge and the evaluation of data representativeness in future progression of karst processes.

\section{STUDY AREA}

The studied zone is located in the central part of the Ebro Basin (NE Spain), which represented the foreland basin to the Pyrenees and the Iberian Chain and evolved as an endorheic evaporitic basin during the Miocene (Pardo et al., 2004). This basin contains different evaporitic facies including mainly gypsum, and other more soluble salts, notoutcropping but identified by boreholes and mining activities (halite and glauberite; Salvany et al., 2007; Salvany, 2009). The drainage system changed after the connection of the Ebro River with the Mediterranean Sea causing the beginning of erosion of the endorheic basin.

The geomorphology of the studied region is characterized by a stepped progression of Quaternary terraces from South to North. The Ebro River is located along the northern border of the alluvial deposits (Fig. 1) and the Miocene evaporitic materials are located at different depths below the Quaternary deposits. Quaternary deposits crop out extensively both to the $\mathrm{S}$ and $\mathrm{N}$ of the studied zone, having thickness between 7 and $15 \mathrm{~m}$. In exposures, evaporitic units are characterized by alternating gypsum and marly levels, while halite is also known in the mining exploitations at Remolinos, less than $10 \mathrm{~km}$ East of the studied zone (Fig. 1); glauberite has also been identified in boreholes in the same area (e.g., Pueyo Anchuela et al., 2010b).

The studied area is located in one of the Holocene terraces near to the transition to the river flood plain (Fig. 1). according to borehole data the water level related to the Ebro river aquifer is $3 \mathrm{~m}$ deep and the evaporitic substratum is between 5 and $7 \mathrm{~m}$ deep. Gravels and interbedded sands forming terrace levels can present carbonate cementations near to the surface. Soils are scarce and only have some centimeters thick when cemented gravels are the outcropping unit.

\section{FIELD EVIDENCE}

This study has been performed in a farming field with an area of nearly $9,000 \mathrm{~m}^{2}$ where agricultural activities ceased because to the high density of collapses developed in the last decades. The surficial evidences are diverse, including open collapses and subsidence zones (Fig. 2). In some cases, collapses are related to cavities located at some centimeters from the surface. These cavities are stable at near-to-thesurface conditions due to the presence of cemented gravel deposits. In these cases no karst evidences preclude collapses; in other cases, concentric cracks surrounding collapses can be mapped.

The vertical sedimentary series identified within collapses comprises a scarcely developed soil and a cemented gravel subsurficial unit interbedded with sands and gravels. Collapses do not permit to identify the original soluble series in the subsoil, but nearby boreholes indicate the presence of a marly grey unit below the terrace level, with variable content of gypsum and alternating gypsum and marls with horizontal bedding.

The evaluation of historical photographs permits to identify the recent evolution of sinkholes since 1927 (Fig. 3); this analysis was completed with a new drone flight performed in 2013 (Fig. 4a). At this moment, different open collapses and topographical depressions having denser vegetation growth can be identified.

In the first evaluated photograph from 1927, the whole studied zone is still cultivated but some black shadows can be identified (this photograph does not have stereoscopic coverage). In more modern 


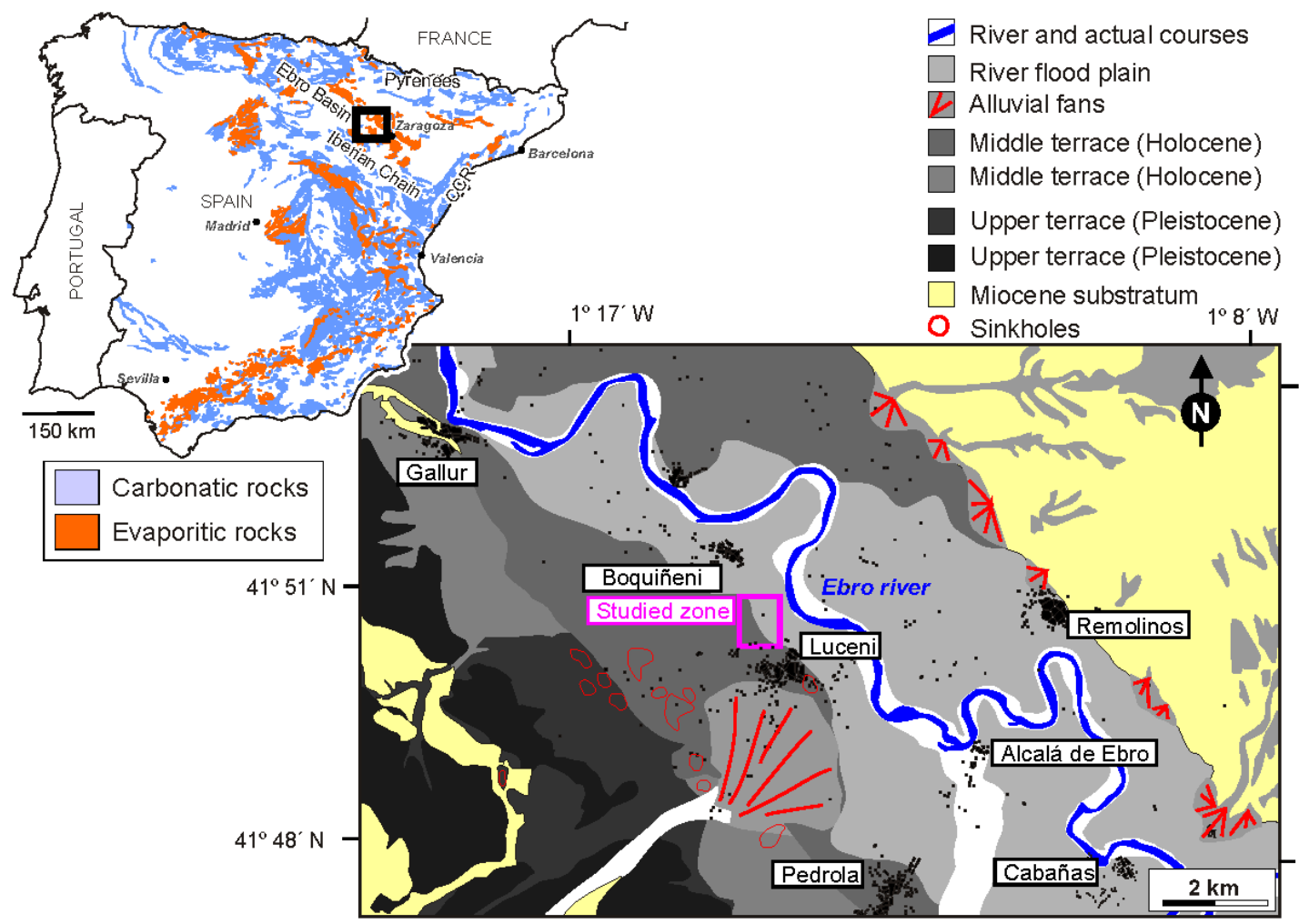

Fig. 1. Distribution of soluble rocks in Spain (modified from Ayala et al., 1986) and geological map of the studied zone (modified from Castiella et al., 1977; Hernández et al., 1995, Esnaola et al., 1995, and Gil Marín et al., 1995).

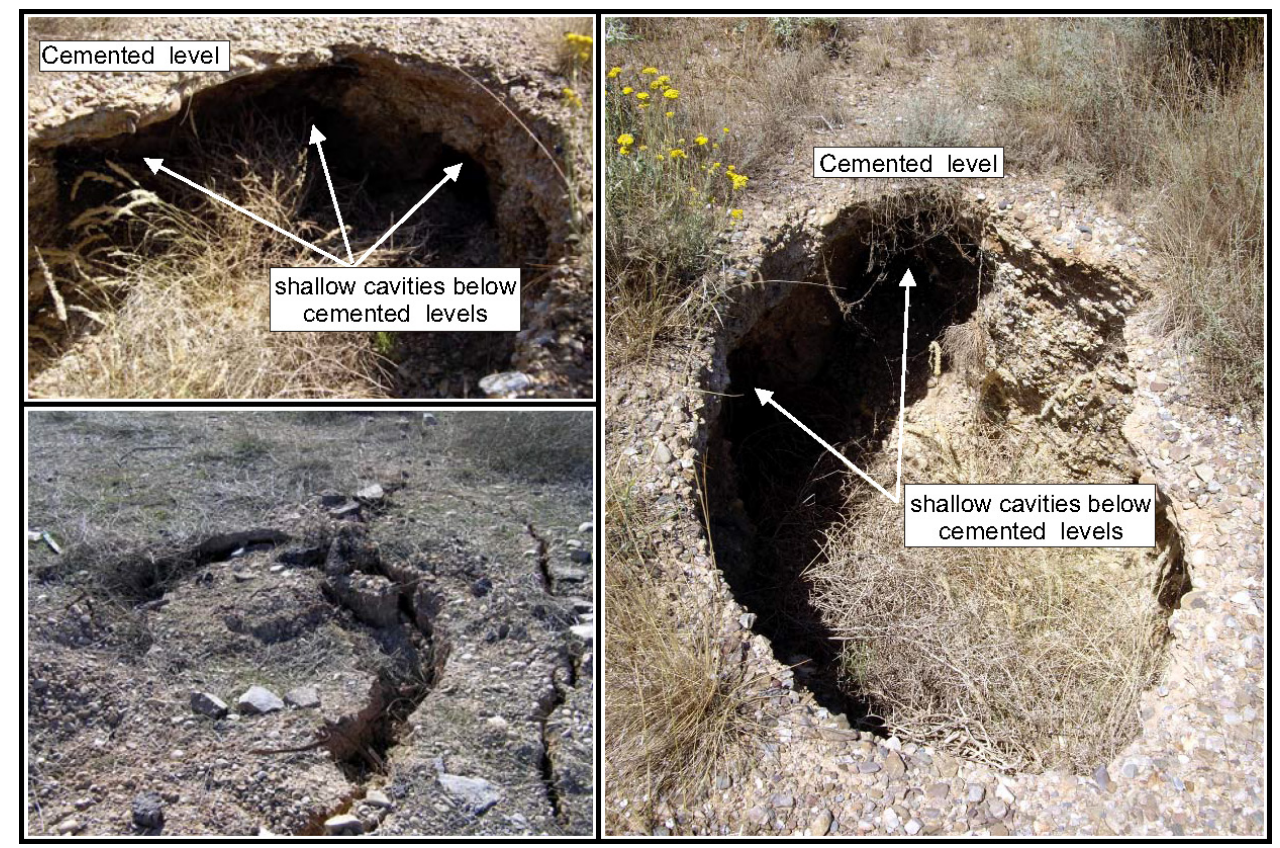

Fig. 2. Field photographs of surficial karstic evidences from the studied area. In the photographs, open collapses and concentric rings of cracks surrounding previous collapses can be identified. Note the shallow cavities due to the presence of a cemented gravel level.

photographs, agricultural activities ceased in several zones; in 1945 the occurrence of collapses led to exclude several zones from cropping. The comparison of this series of photographs with the recent drone flight permits to make some general remarks about the present-day features of the studied zone. On one hand, distinct collapses (e.g., 1956 in the eastern sector close to the road; dotted zone in photographs shown in Fig. 3) are identified, whereas in the 2013 photograph this area is associated with a wide subsidence area that exceeds the 1956 collapse (see Fig. 4a for the present-day aspect). Something similar can be observed in most of the collapses identified in the aerial photographs that present densely vegetated areas with slight topographical changes. The fact that topographical changes disappeared in recent times is interpreted in terms of collapse filling and recent soil development. The presence of a shallow, strongly cemented level precludes quick vegetation growth, and therefore aromatic plants such as thyme, rosemary and wild chamomile expand in those areas These differences permit to relate the presence of grass growth with previous collapses and subsidence zones. 


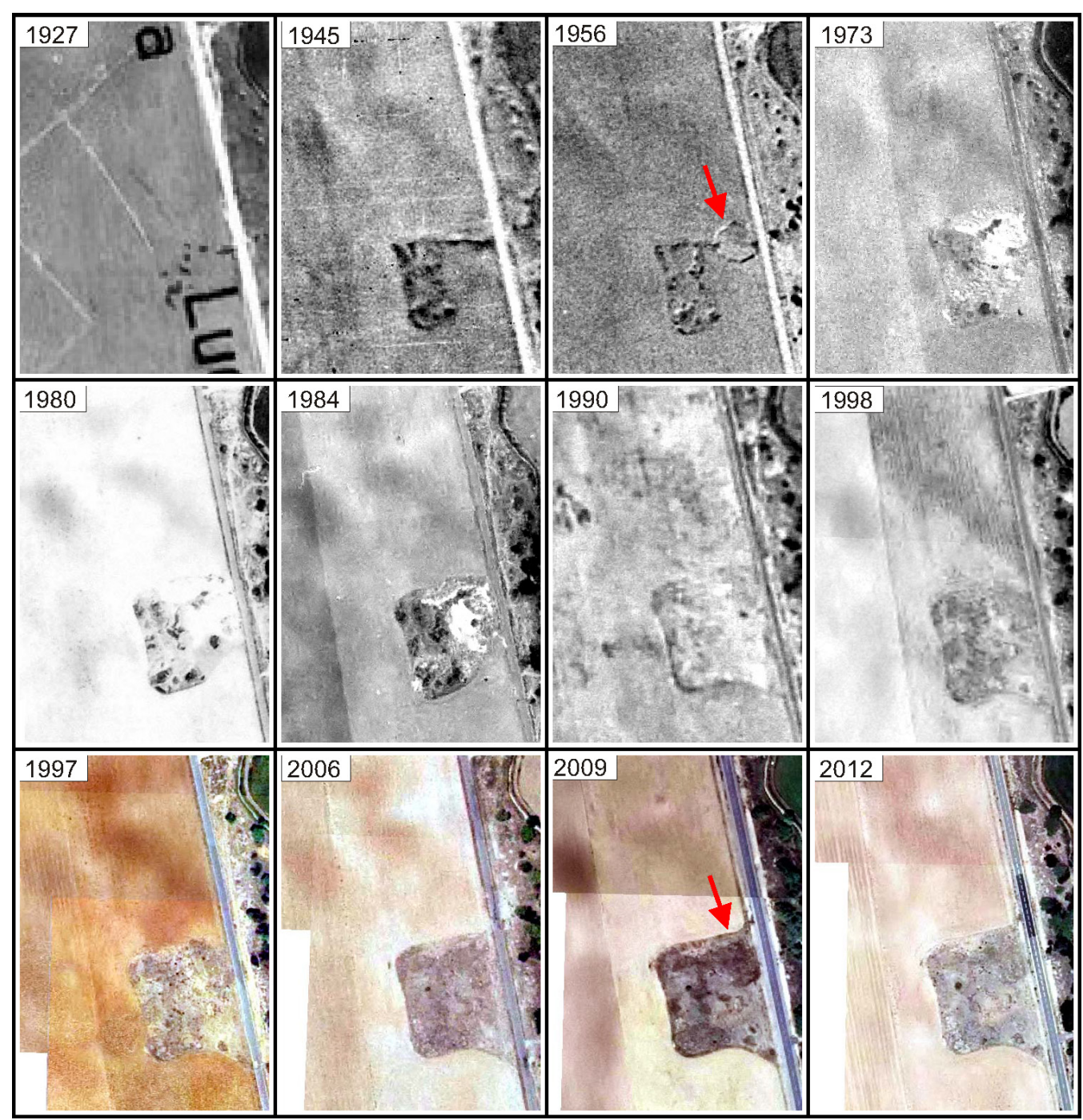

Fig. 3. Collection of aerial photographs showing evolution of cavities from 1927 to 2012 . The main anomaly described in the text is marked by an arrow.

\section{GEOPHYSICAL METHODOLOGY}

A dense geophysical campaign, including magnetometry, multifrequency electromagnetic (EM) survey and ground penetrating radar (GPR) using different central frequency antennas was performed.

Magnetometry was carried out with an Overhauser proton magnetometer with GPS as rover through a systematic, two normal directions survey including the whole barren area (Fig. 4b). Control of diurnal changes of the Earth's magnetic field was carried out with a second magnetometer as base during the survey. Diurnal correction was carried out and residual and vertical gradient magnetic data were used to draw maps. EM and GPR surveys were carried out through parallel profiles geolocated by GPS at the ends. Due to this survey manner, the zone surveyed with EM and GPR was reduced to a rectangular area respect to magnetometry.

EM was performed along parallel profiles in one direction (Fig. 4c) using a GEM-2 device with 5 different frequencies ranging from 0.5 to $65 \mathrm{KHz}$ (Huang, 2005). The survey consists in the measurement of in-phase and quadrature waves allowing for the apparent conductivity and apparent susceptibility of subsoil materials to be calculated for each frequency (Huang \& Won, 2000). These frequencies represent, for average soils, survey depths between 5 to $25 \mathrm{~m}$ from the surface, penetrating the whole alluvial series and the upper part of the evaporitic substratum. From the obtained results, maps of apparent conductivity and susceptibility for each frequency were obtained.

GPR profiles were performed with a CUI-2 unit from RAMAC with 50, 100 and $250 \mathrm{MHz}$ antennas through parallel profiles (Fig. 4d). Based on the obtained results, the detailed analysis presented in this work makes reference only to $100 \mathrm{MHz}$ profiles that permitted the evaluation of the whole alluvial series. In all the profiles, the surveyed depth is similar, being equal for 50 and $100 \mathrm{MHz}$ because of the existence of a conductive contact in the subsoil, and lower for the $250 \mathrm{MHz}$ antenna. Processing of data consisted in filtering of frequencies out of range from the central frequency of the used antenna, running average for smoothing small changes due to vegetation, and lineal and exponential gain filtering and subtracting of mean trace to avoid the usual banded horizontal distribution in GPR profiles. Propagation velocity was calculated from the geometrical analysis of hyperbolic anomalies, although the exact position of reflectors was not the main objective of this analysis. In addition to the described geophysical prospection, a topographic survey was also performed for the general 
a) Drone flight photograph

b) Magnetometry survey

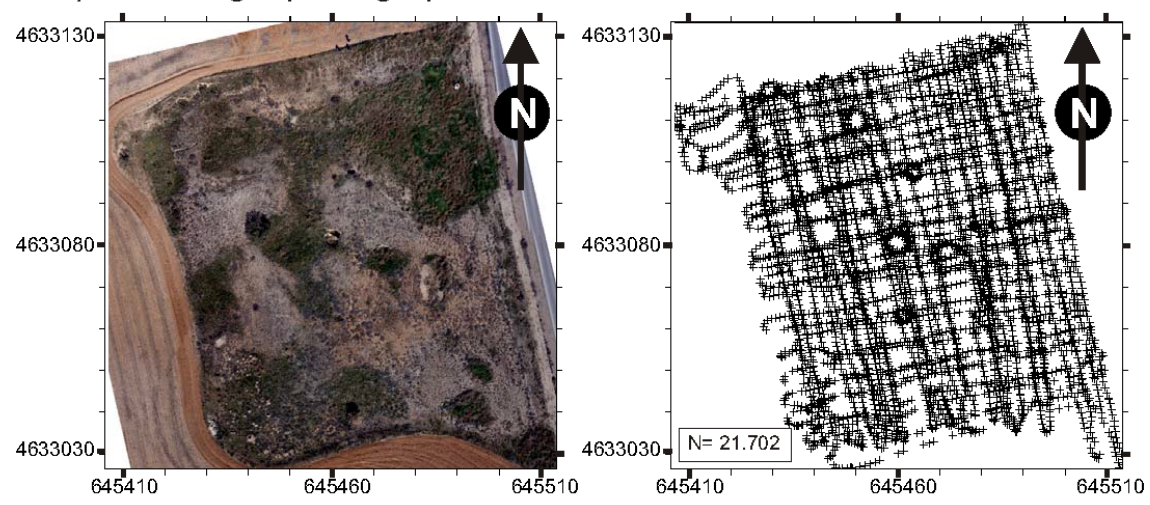

c) EM profiles

d) GPR profiles

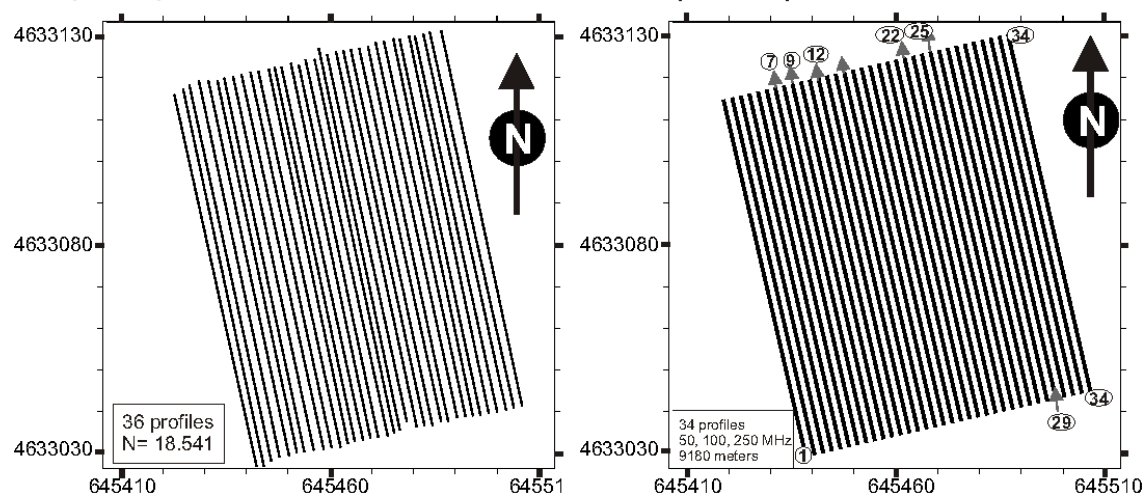

Fig. 4. a) Drone flight performed in 2013; b) rover tracks of the magnetometry survey;

c) location of EM profiles performed; d) location of GPR profiles (some of the named profiles are included in others).

evaluation of the studied zone (Fig. 5b). Topographic changes are not significant except along the marginal areas, at the contact with the cropped areas and along the eastern sector. Differences in elevation hardly reach $1 \mathrm{~m}$, but most part of the studied zone only presents changes of some decimeters.

\section{GEOPHYSICAL RESULTS}

Two different maps were constructed from magnetic data including the intensity of the Earth's magnetic field (Fig. 5c) and vertical magnetic gradient (Fig. 5d). Both maps present very similar results. Magnetic data permit to identify a clear magnetic dipole, identified both at total field intensity and magnetic gradient maps, at the central zone of the southern border ( $\mathrm{S}$ anomaly in Fig. $5 \mathrm{c}$ and d). Other dipoles show a poorly defined negative part, and in some cases only the positive peaks are clearly identified. In addition to these changes, the NE sector ( $\mathrm{NE}$ anomaly in Fig. 5c and d) also shows a particular cluster of magnetic anomalies. Several dipoles can be identified, some of them at the borders of the surveyed zone. However, a general increase of total intensity, depicting a crescent shape open to the $\mathrm{E}$, can be defined. In detail it can be described as containing two clear dipoles with a nearly E-W orientation at the south and north and a heterogeneous domain in-between (see changes in the vertical gradient in Fig. $5 c$ and d).

EM data coincide with the magnetic anomalies, especially along the zone with anomalous behavior at the northeastern sector (Fig. 6), showing an increase of apparent conductivity. The wavelength of anomalies decreases as frequency increases: shorter when using the $475 \mathrm{~Hz}$ frequency (deeper interval; Fig. 6a), and longer for $18 \mathrm{KHz}$ (Fig 6b) and $65 \mathrm{KHz}$ (Fig. 6c). Another interesting peak (see Fig 6a, d, and e) coincides with the most important magnetic dipole shown in Fig. 5. This anomaly is also identified in the apparent susceptibility maps for the lower and intermediate frequencies (Fig. 6d, e). The NE anomaly also shows an increase in apparent susceptibility. The higher frequency maps do not show clear anomalies but rather a progressive change from $\mathrm{W}$ to $\mathrm{E}$ and low apparent susceptibility values (Fig. 6f).

The GPR survey shows an irregular distribution of penetration, from $7 \mathrm{~m}$, which is the expected thickness of the alluvial deposits, to some decimeters (Fig. 7a). These changes in penetration can be gradual, defining plane-concave geometries, or sharp, showing subvertical lateral limits. The low penetration areas are surrounded by on-lap geometries that define a deepening of reflectors towards the low penetration area (see northern sector of profile 7 at Fig. $7 \mathrm{a}$, for example). Moreover, the analysis of the GPR profiles also shows reverberations, especially in the western profiles. It is interesting to note that the survey area is free of pipelines or other metallic elements, and some of these anomalies can be followed along parallel profiles or define irregular sectors (some of these anomalies are marked at profiles in Fig. 7a). Other irregularities identified in the GPR-profiles are related with the loss of definition of reflectors in some of the areas where high penetration is achieved (see marked domains at Fig. 7a). 
a) Drone flight and profiles location

b) Topograhic map
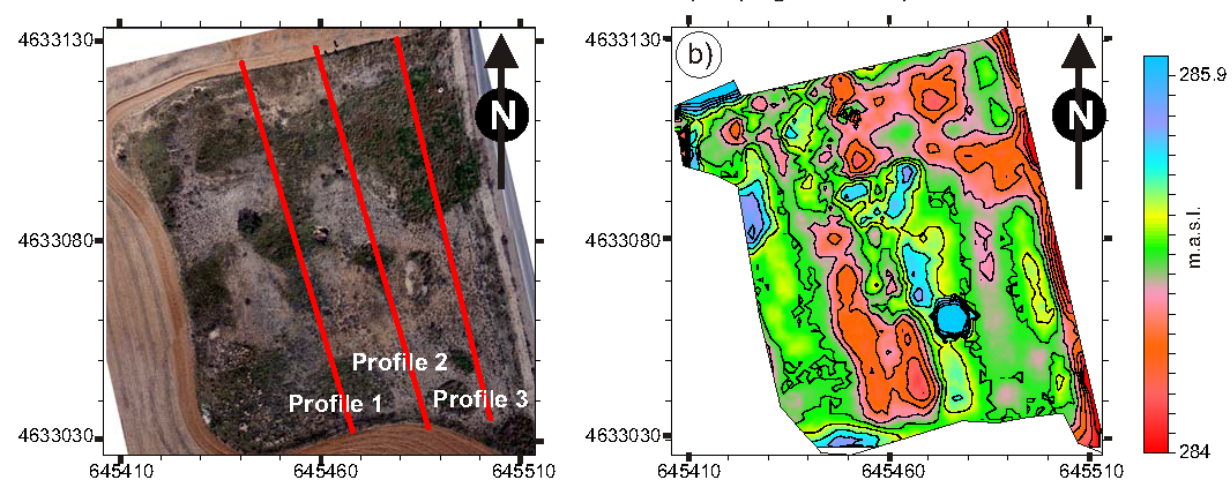

c) Residual Earth Magnetic field map

d) Vertical magnetic field gradient
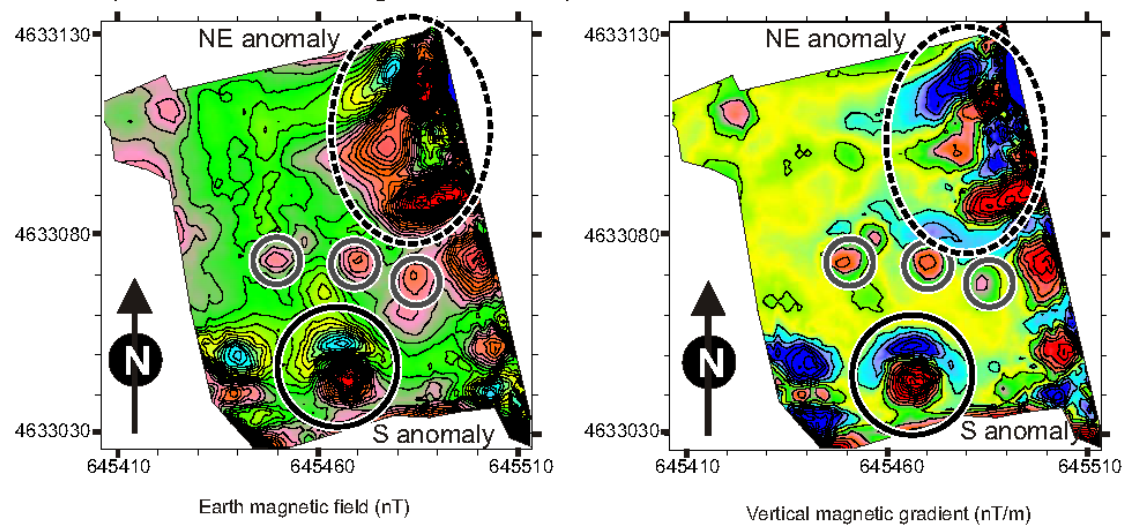

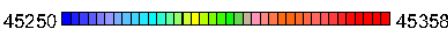

-8 Vertical magnetic gradient $(\mathrm{nT} / \mathrm{m})$

Fig. 5. a) Drone flight from 2013 showing the area where the geophysical survey has been carried out and the location of main profiles described in Fig. 8; b) Topographic map; c) Earth magnetic field intensity map and d) vertical magnetic gradient map. In both c) and d) the main described anomalies are also marked.

\section{Apparent conductivity maps}
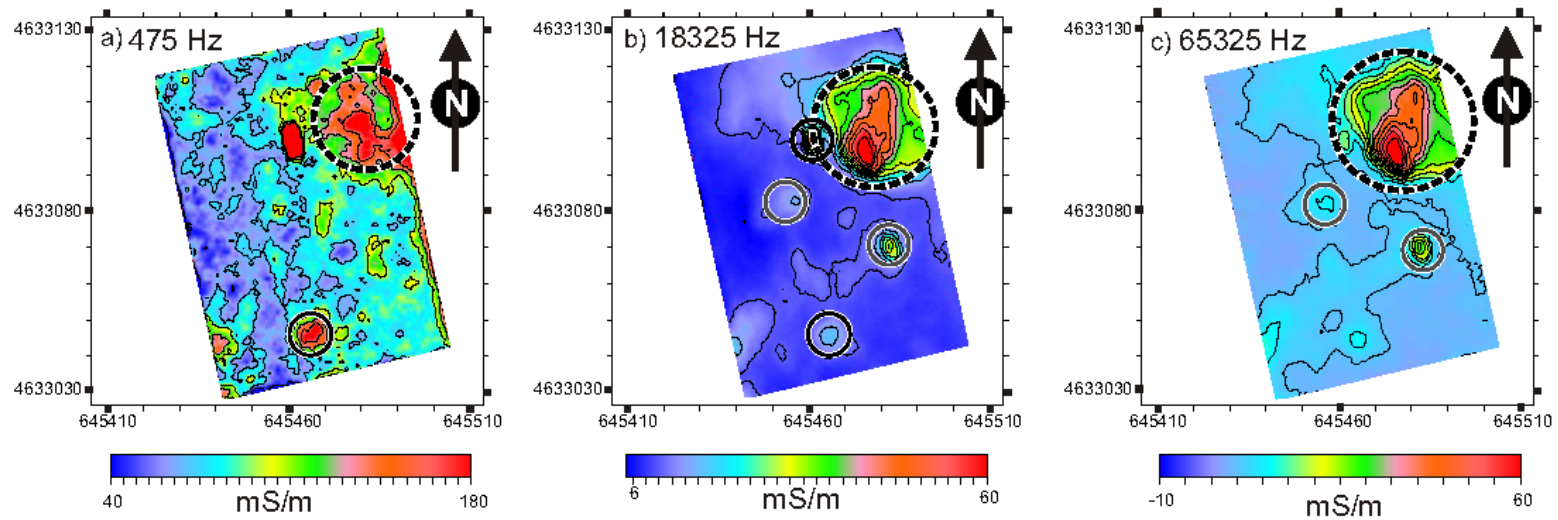

\section{Apparent susceptibility maps}
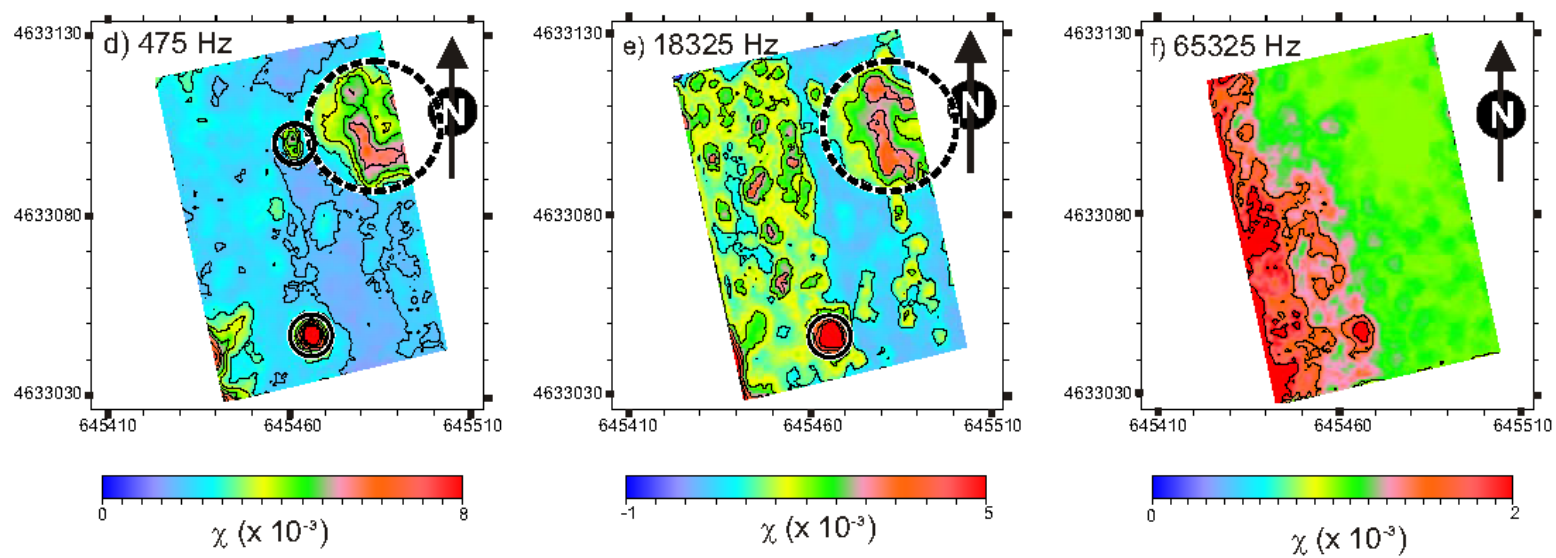

Fig. 6. Main results obtained from the multifrequency electromagnetic (EM) survey including three different frequencies for a, b, and c) apparent conductivity and d, e, and f) for apparent susceptibility. The presented frequencies are 4750, 18325, and $65325 \mathrm{~Hz}$, respectively. Some of the main identified anomalies are also marked. 
a) GPR results

SSE
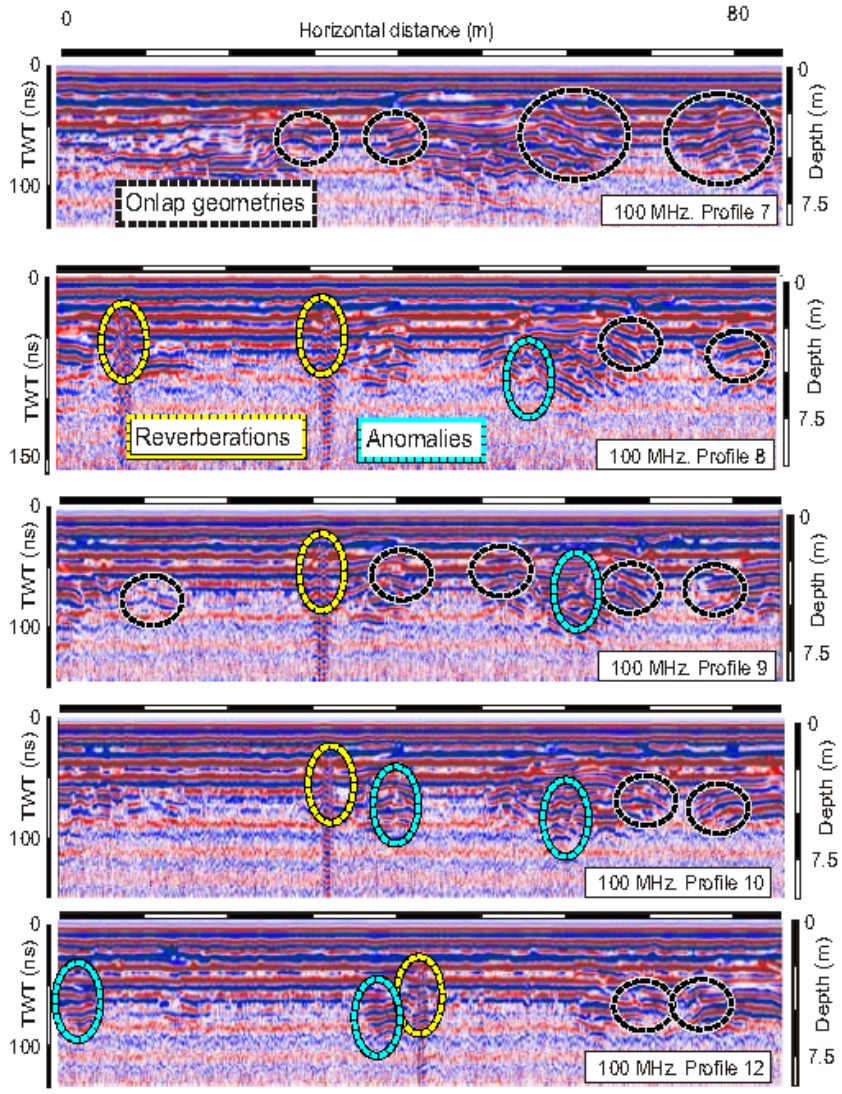

SSE

NNW

BO
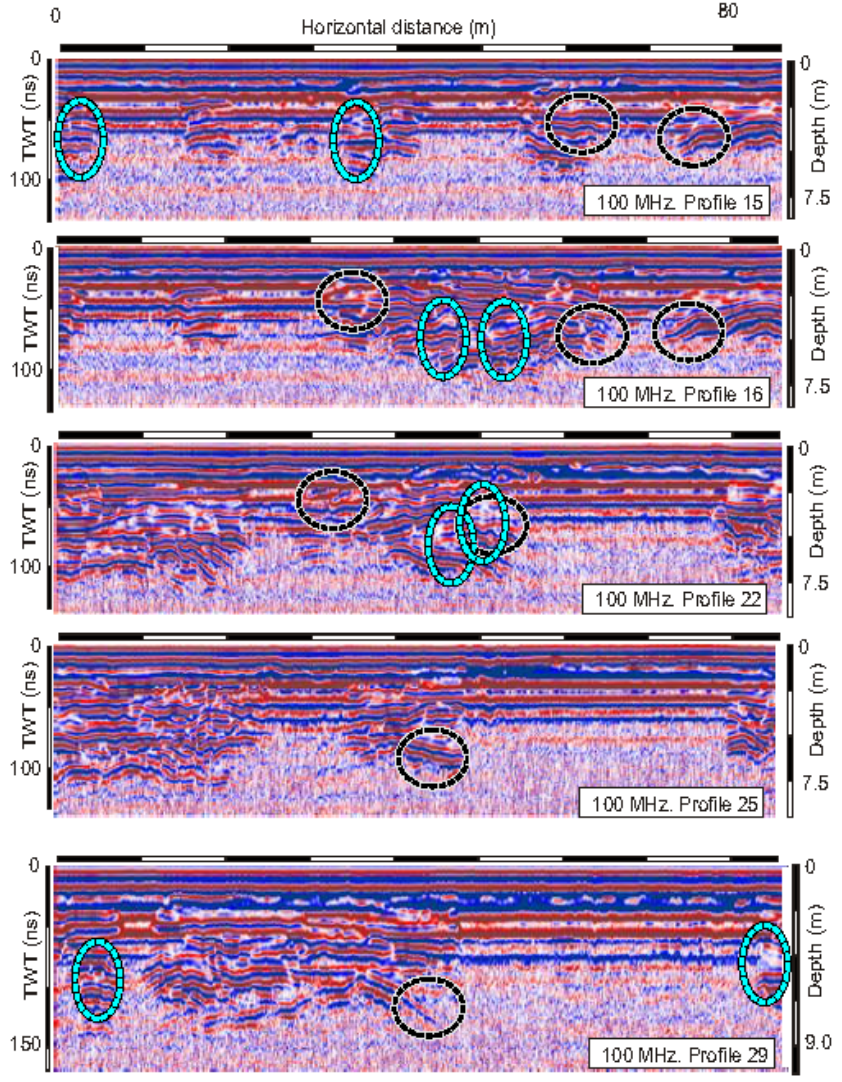

b) Apparent reflectivity map (shallow interval) c) Apparent reflectivity map (deep interval) d) GPR penetration map

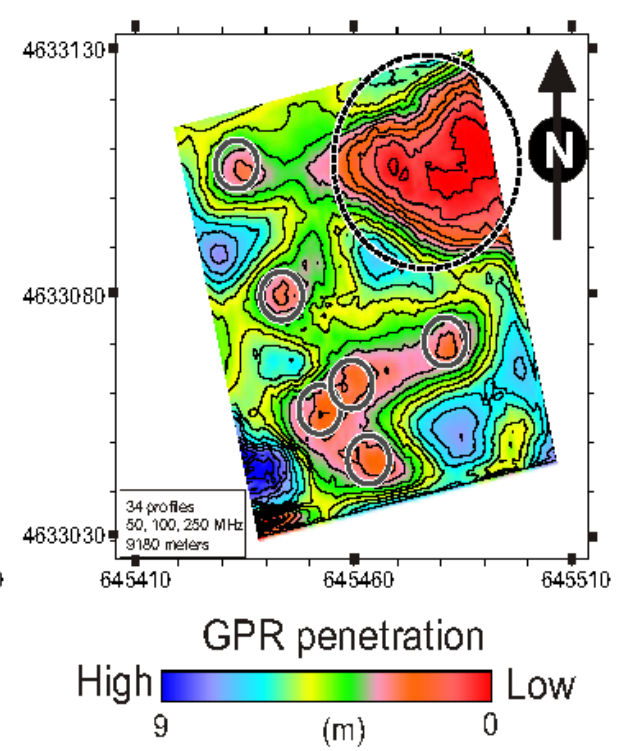

Fig. 7. Main GPR results. Different profiles carried out with the $100 \mathrm{MHz}$ antennas are included (see Fig. 4d for the GPR profile location). Over the profiles different types of anomalies have been included making reference to the geometrical changes defining on-lap geometries pointing to subsidence zones, reverberation domains and low definition of reflectors within reflective media; b) Apparent reflectivity map for shallow intervals; c) apparent reflectivity map for deep conditions; d) map of penetration of GPR survey. Anomalies are marked using the same drawing used in Figs. 5 and 6.

GPR data have also been subjected to two additional evaluations: 1) Apparent reflectivity maps have been performed in order to compare the changes of penetration and reflectivity of GPR data (Fig. 7b and c; see Pueyo Anchuela et al., 2011c for methodology). These results define a NE sector with highly reflective behavior and some isolated peaks in near-to-thesurface maps. At deeper levels, well defined circular geometries are identified (Fig. 7c), coinciding with some of the previous anomalies identified by previous techniques, and 2) Analysis of reached depth of the GPR penetration (Fig. 7d). A NE sector and a southern domain with low penetration against sectors with higher penetration can be distinguished, in agreement with the expected thickness of alluvial deposits. 


\section{DISCUSSION}

\section{Integrated evaluation}

The described results show different signatures that can be interpreted, according to the surficial and historical inventory, and the well-constrained geological model, to karstic evidences. Some of the identified anomalies permit the direct correlation between techniques and indicators, whereas other anomalies are not identified in all of the techniques or present different sizes or distributions. In order to evaluate these changes, three different sections (profiles 1-3 in Fig. 8) that include some of the main identified anomalies, have been constructed (see Fig. 5a for profile location). These sections integrate historical, geomorphological and field inspection information with the data obtained from geophysical analysis. This comparison permits to establish general considerations about collapses observed in aerial photograph, that generate magnetic anomalies reaching amplitudes of $60 \mathrm{nT}$ coincident with conductivity anomalies and decrease of GPR penetration depth (e.g., southern sector of Fig. 8a). These anomalies can be explained by the use of urban debris in the collapse filling. This filling contains ferromagnetic elements, showing higher values of magnetic susceptibility than local natural materials. The presence of urban debris at surface overlying previous historical collapses confirms this interpretation (see for example Mochales et al., 2008).

Other magnetic dipoles do not show a direct correlation with the apparent conductivity anomalies. In this case, magnetic dipoles are included within the conductivity and susceptibility anomalies and can be related to subsidence sinkholes inferred from aerial or surficial data (case of the northern domain of profiles shown in Fig. $8 \mathrm{~b}$ and c). In these sectors penetration depth of GPR is severely limited. In other cases, magnetic dipoles coincident with collapses in the aerial photographs are identified in the marginal areas of the conductivity anomalies and subsidence sinkholes. This is the case of the collapses surrounding the subsidence zone having a conductivity anomaly and low GPR penetration located in the central-northern sector of the profile shown in Figure 8c.

The map view distribution of anomalies can also help in the interpretation and integration of results obtained from the different used techniques and approaches (Fig. 9). In order to evaluate the map view distribution of indicators, the size of the anomalies has been established following simple geometries that include the anomalous areas, depending on the particular characteristics of each technique. Some of the anomalies coincide in all the maps, while others are only identified in some of them. A first data evaluation permits to identify a strong parallelism between the maps obtained from historical evolution of geomorphological evidences and the geophysical maps. A simplified map (Fig. 10) considering the amplitude of the anomalies shows clear correlations between the NE sector coincident with a collapse in the 1956 photograph, and a subsidence zone with higher vegetation growth in the rest of aerial photographs on one side, and: (i) an overall increase of magnetic field intensity, the occurrence of two groups of dipoles with a general E-W distribution and a heterogeneous behavior in vertical gradient, (ii) an increase of both apparent conductivity and susceptibility, (iii) a zone having very low GPR penetration surrounded by onlap geometries pointing towards the center of the anomaly, and (iv) recent collapses surrounding the marginal areas of the subsidence zone, on the other.

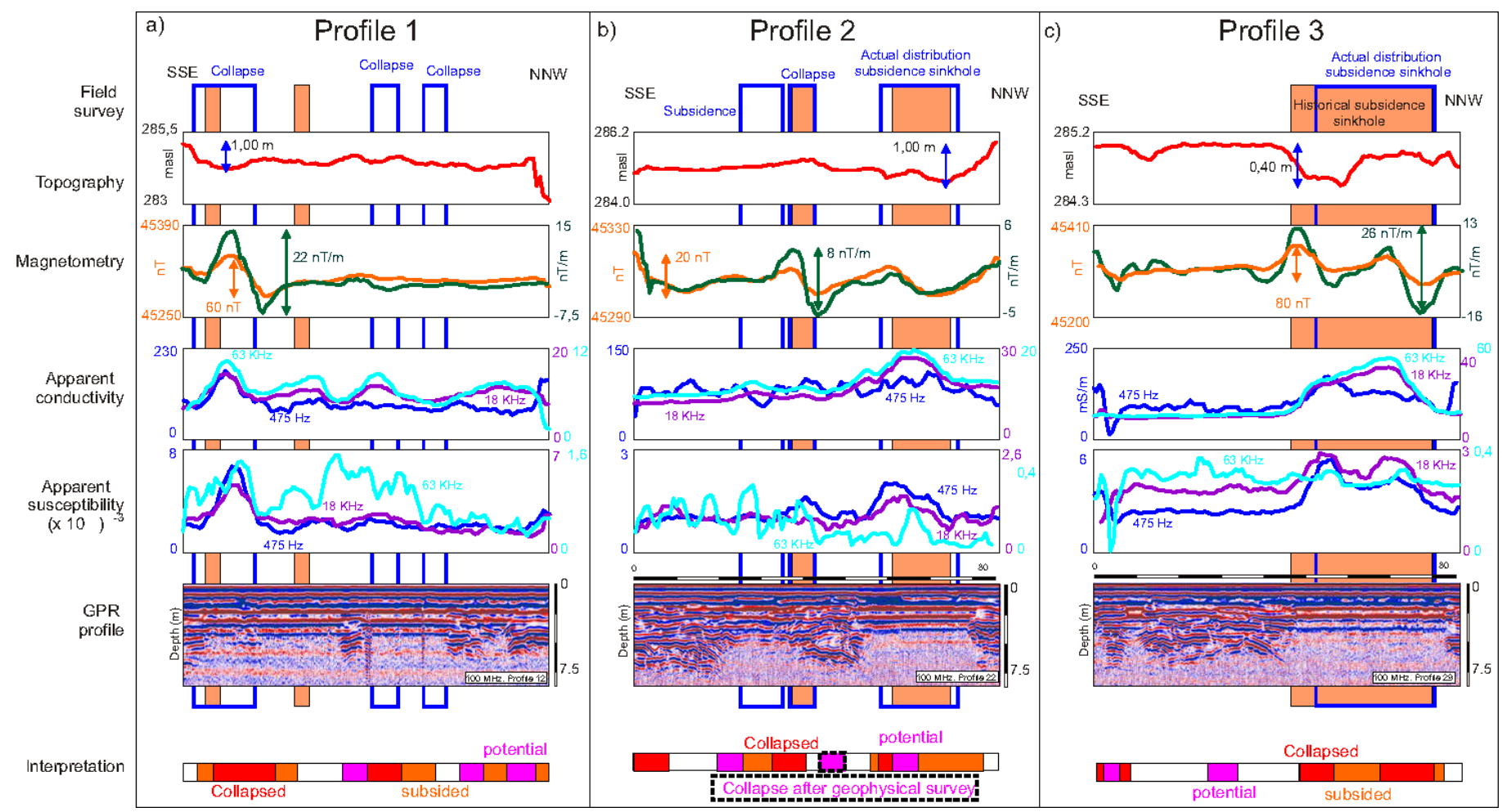

Fig. 8. Comparison of geophysical results in three profiles (see Fig. 5a for location) including the different evaluated approaches and their interpretation and correlation. The three profiles include the main described anomalies, namely (from E to W): a) profile 1; b) profile 2 and c) profile 3 . The recent collapses postdating the geophysical survey are included in the central section. 


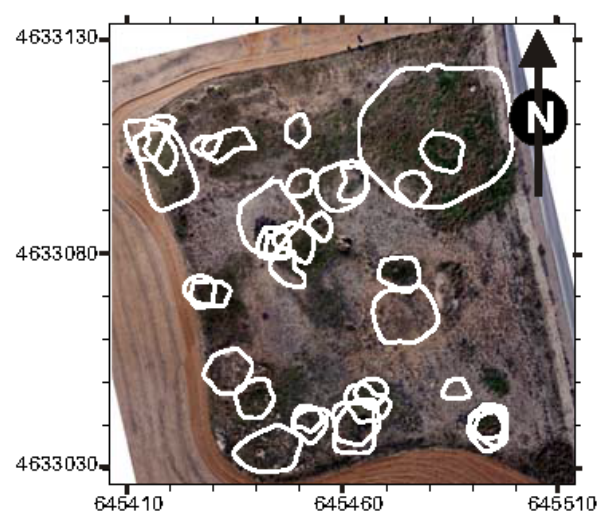

(O) Historical collapses and subsidence areas

APPARENT CONDUCITVITY ANOMALIES

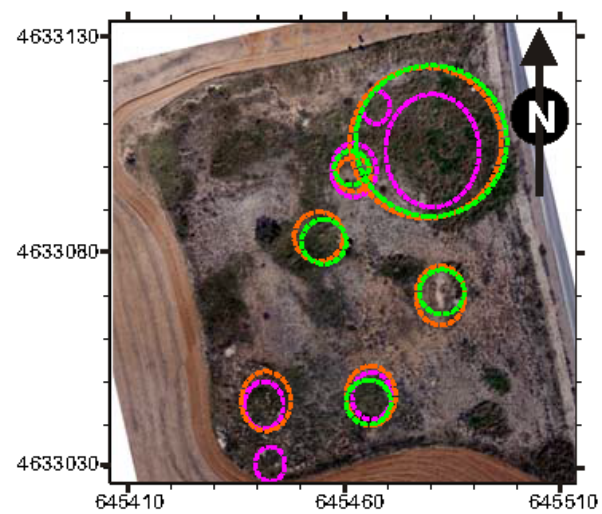

APPARENT SUSCEPTIBILITY ANOMALIES
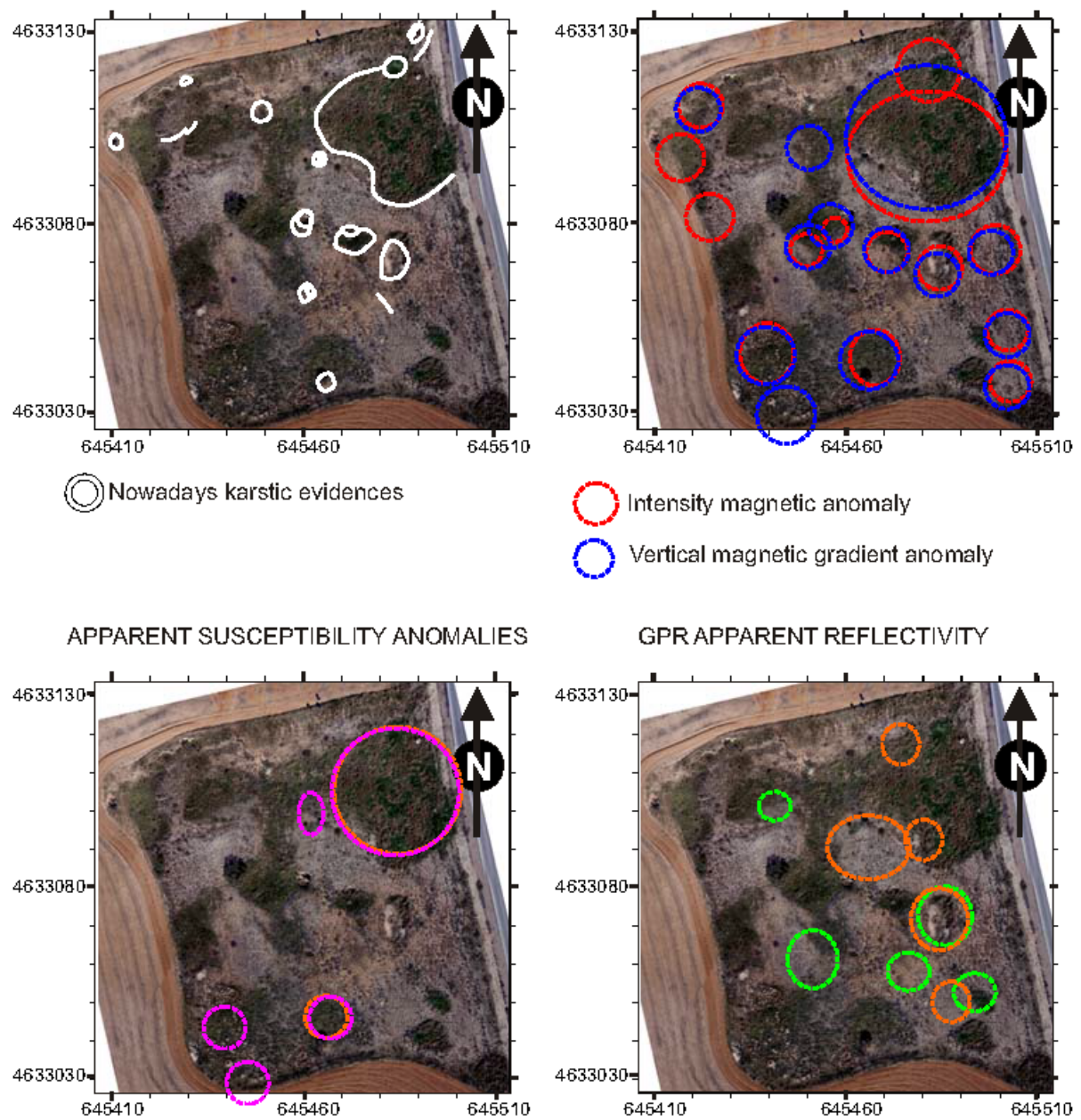

(-) Intensity magnetic anomaly

(.) Vertical magnetic gradient anomaly

\section{GPRAPPARENT REFLECTIVITY}

Shallow anomalies

intermediate anomalies

Deep anomalies
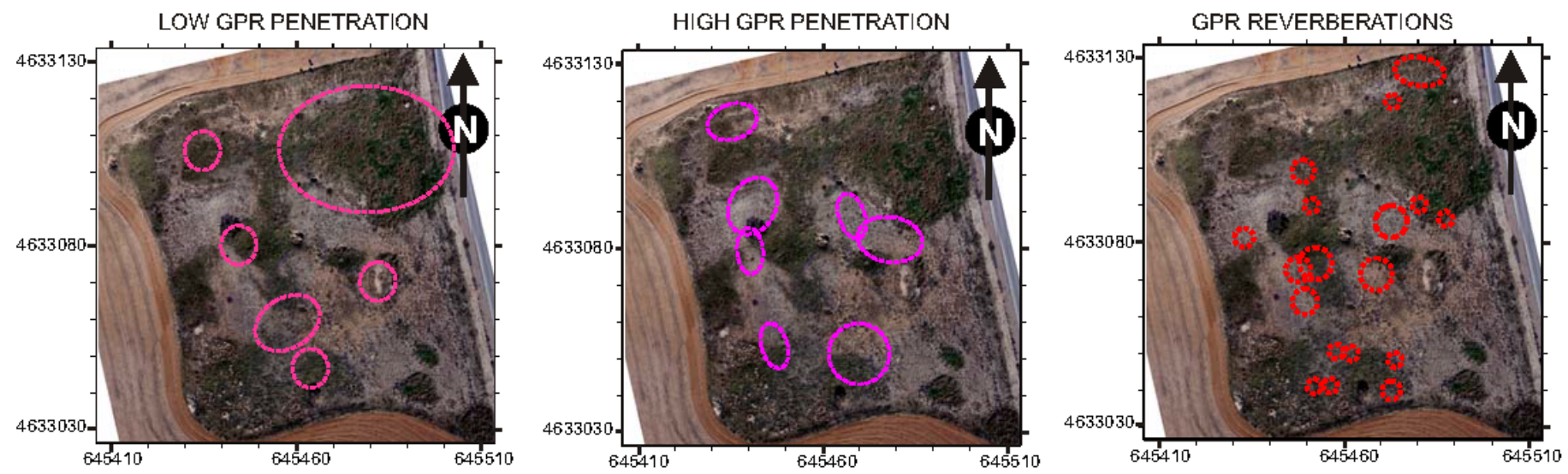

() highly attenuated areas

Fig. 9. Map of geomorphological karst evidences and geophysical anomalies for the different geophysical techniques and methodological approaches.

In other cases, sharp peaks in magnetic intensity/ gradient, apparent conductivity or susceptibility and reduction of GPR penetration correlate with isolated collapses identified in the aerial photographs that have been subsequently filled.

The comparison of geophysical data with geomorphological evidences shows that geophysical (GPR and electromagnetic) anomalies usually exceed the limits of geomorphological collapses, whereas apparent susceptibility or magnetic anomalies are similar in size. Field inspection shows that sectors associated with previous collapses present wider extension of vegetation growth and smaller topographical changes than the true collapses. In other cases, as for example the recent collapses related to open cavities, the geophysical signature in magnetometry and EM is usually poor and they occur in sectors with high penetration of GPR data.

\section{Sinkhole progression model}

The integrated data evaluation permits to describe the evolution of sinkholes over time and to define the geophysical signatures that can be used as 
Historical photographs
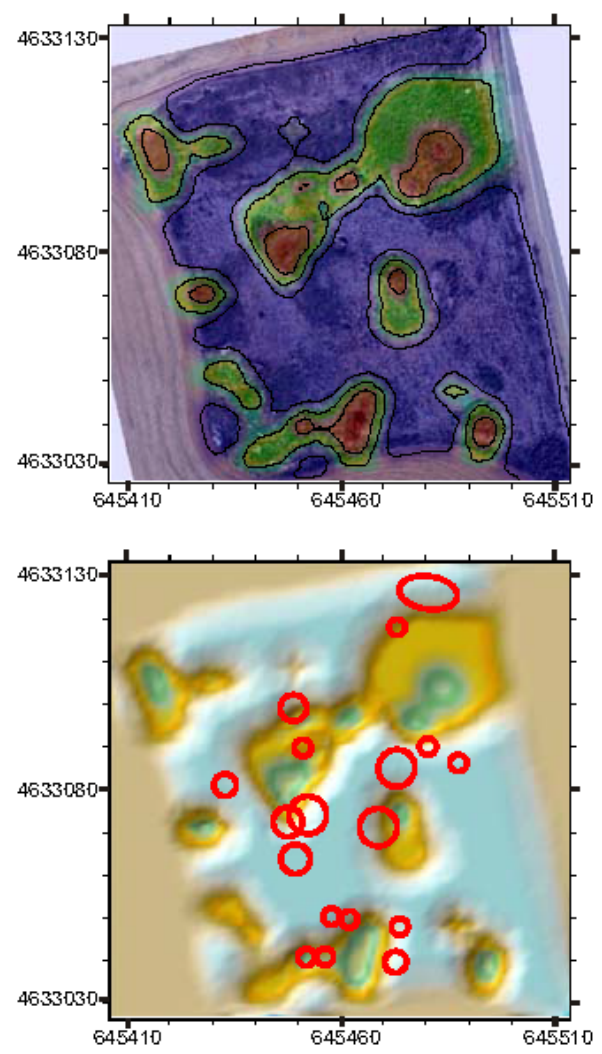

Electromagnetic
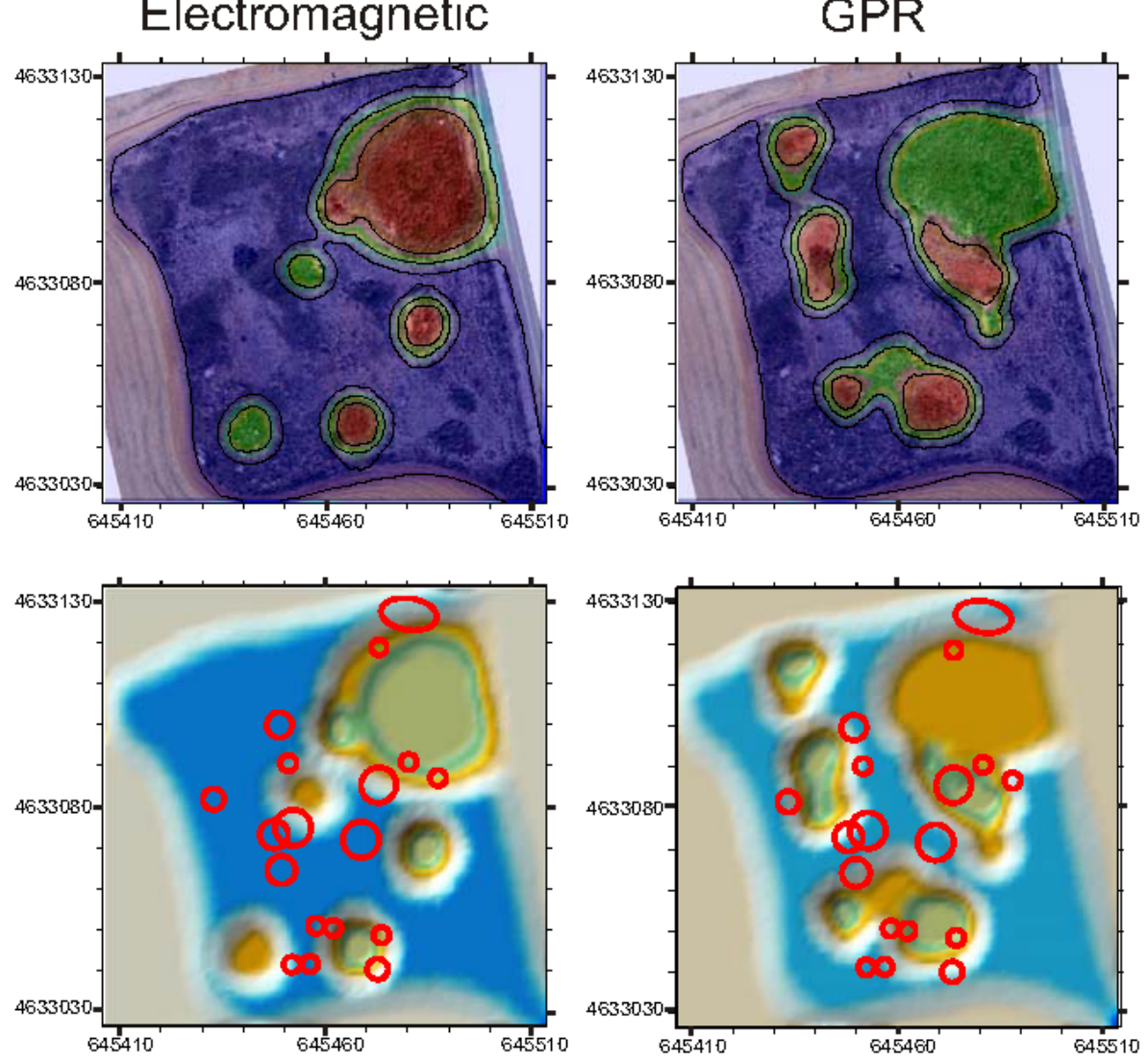

Nowadays state
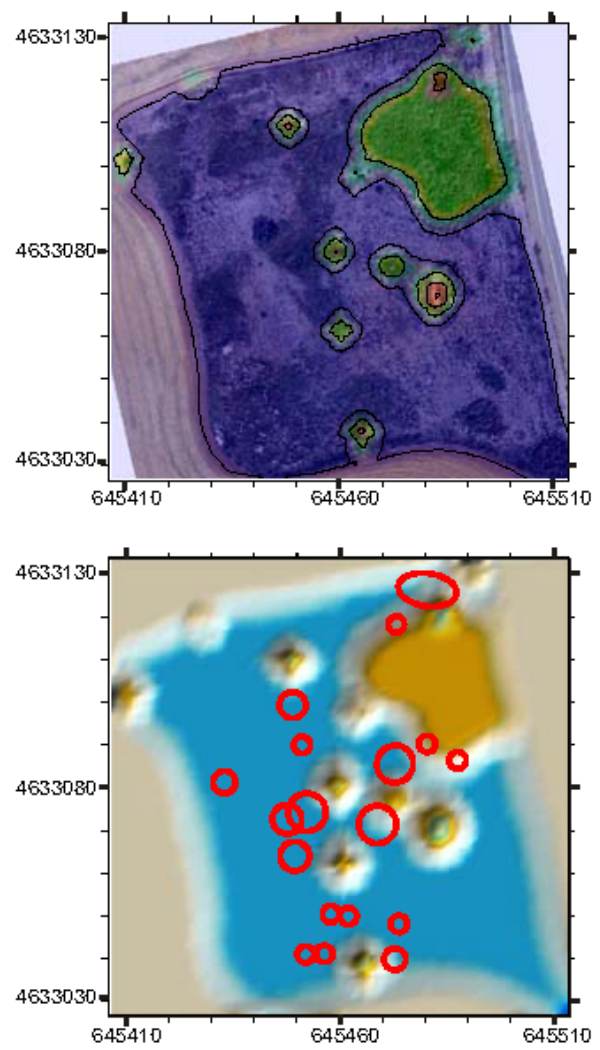

GPR

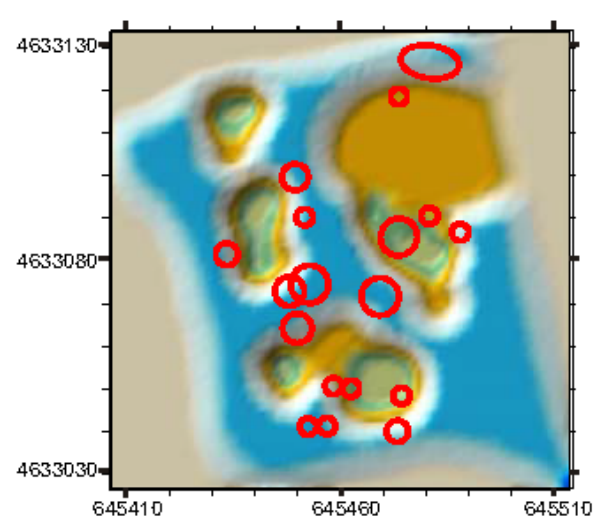

Magnetometry
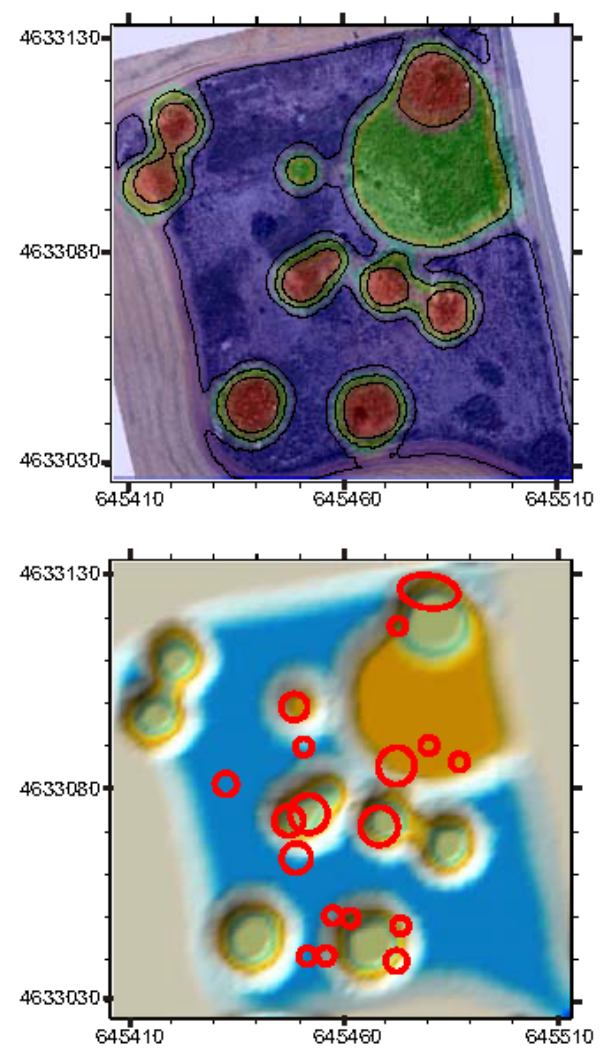

GPR penetration
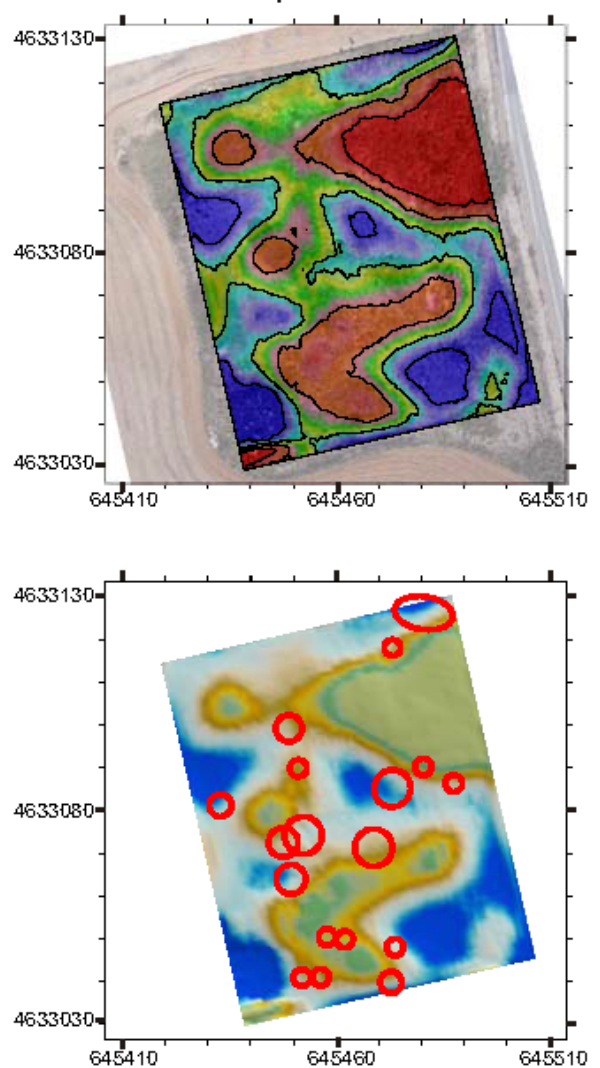

Fig. 10. Cartography of the studied changes in the surveyed area considering the extension of interpreted collapses and subsidence areas from historical and recent geomorphological evidences, magnetometry (intensity and vertical magnetic gradient), electromagnetic apparent conductivity and susceptibility integrated results, GPR distribution of interpreted subsidence and collapse zones and GPR penetration for the $100 \mathrm{MHz}$ antennas. The location of reverberation and net hyperbolic anomalies identified in the GPR profiles is superimposed on the plots. 
indicators of their evolutionary stage. Due to the good record of aerial photographs, this evolutionary model can be followed and compared with the geophysical data.

The sinkhole located in the NE sector shows the clearest evidences: it is identified as a preliminary collapse in the 1956 photograph, and was subsequently filled as indicated by vegetation growth. At present, there exists a topographical depression that engulfed the collapse and developed several marginal collapses. This geomorphological description can be interpreted in terms of an initial cavity propagated from the substratum, that can persist in near-to-thesurface conditions due to the presence of a highly cemented level, which progressed to finally form an open collapse. This collapse was filled, at least in the studied zone, by anthropogenic activity, and the filling was colonized by vegetation and soil development. The sinkhole increased its size and concentric cracks and collapses appeared surrounding the previous collapse.

The evaluation of the rest of the studied zone permits to identify other different stages of the same process showing shallow cavities, open collapses, and collapses filled by natural or anthropogenic materials. Some of them were affected by later subsidence and increased in size.

These data can permit the interpretation of collapses filled by anthropogenic materials by means of the well-developed magnetic dipoles or lower amplitude anomalies when the filling is composed of natural materials. In other anomalous sectors, a parallelism between subsidence zones surrounding collapses with moderate positive magnetic anomalies (tens of nT) and clear increases in apparent susceptibility and conductivity and low penetration of GPR data is identified. In these cases, this penetration change is interpreted in terms of an increase of clay content in the developed soils at the overall subsidence zone exceeding the observed collapse. This evolutionary model defines the location of cavities at sectors surrounding previous subsidence areas that later produce open collapses. GPR reverberations and low definition of GPR-reflectors at high penetration sectors usually surround previous subsidence zones. These GPR reverberations, hyperbolic anomalies or low definition of reflectors do not show clear correlation with magnetic data, although slight decreases of apparent susceptibility can be identified over some of these anomalies. In this sense, this kind of anomalies could be the expected signature of shallow cavities but they cannot be directly correlated with results from other techniques (Fig. 10). These anomalies coincide with those identified by other techniques or define clusters around previous evidences of karst activity.

During the stage of interpretation of geophysical data, after the drone photograph and the geophysical survey (April 2016), a new collapse was identified. This new collapse (Fig. 11) can be used as a test for geophysical data. In this sense, the location of the collapse (included in Fig. 8b along the central profile), was compared with the geophysical data obtained over the cavity before the recent collapse.

The collapse happened in a sector with high penetration of GPR, low definition of reflectors or a nearly transparent record at GPR profiles and near to one of the described reverberations. The other geophysical techniques do not show significant anomalies, at least at the exact position and size of the new collapse. This contrasting result permits to establish the resolution limits of magnetometry and EM techniques to predict new collapse development vs. GPR, which shows potential anomalies that can be interpreted in terms of shallow cavities.

In this sense, hazard evaluation presents limitations for the prediction of future karst development at least from the perspective of historical and geomorphological inventory and some of the evaluated geophysical techniques. Moreover, in noncohesive covers, hazard zoning is usually based on the distance to the sinkholes (higher hazard close to existing sinkholes). However the propagation in the vertical (subsidence phenomena in previous collapses that will evolve progressively due to solution processes), and horizontal directions, due to the increase of their radii by formation of new cavities surrounding the subsidence areas, are the cause of hazard concentration in marginal areas of previous sinkholes. In this context (changing rheology within the alluvial cover), the most hazardous areas are shifted towards the marginal areas (collapses) respect previous sinkholes (subsidence).

\section{CONCLUSIONS}

The evaluation through a multi-technique and multimethodological approach has permitted to identify the expected evolution of karstic phenomena in a context of mantled karst having shallow cemented levels. This evolution is related to the presence of soluble materials in the substratum that results in upward propagation of cavities, where they are metastable until the alluvial, non-soluble cemented level collapse.

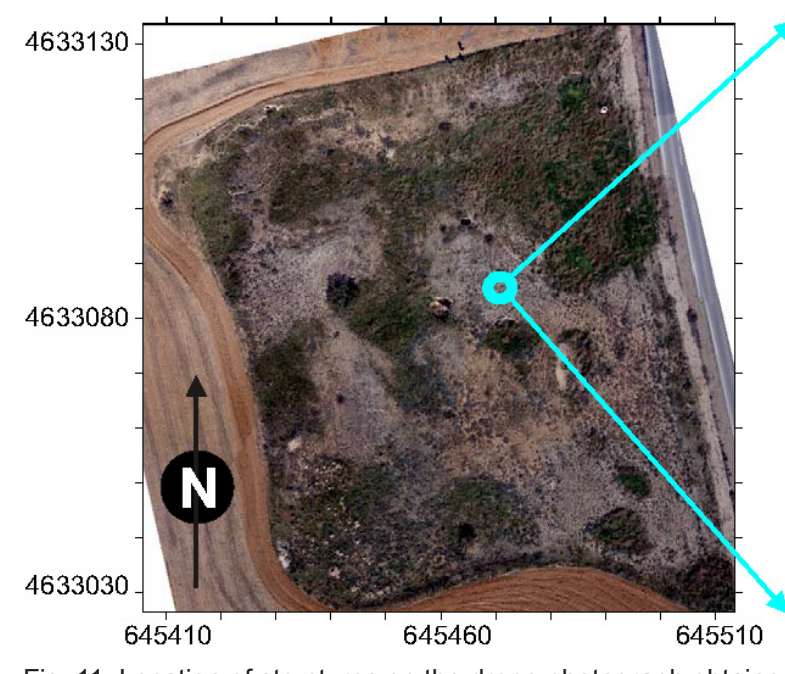

Fig. 11. Location of structures on the drone photograph obtained in 2013 including the collapse identified during April 2016. Field photographs of the 2016 collapse are also included. 
Karst evolution in this setting can be described through different stages including a collapse that subsequently becomes a subsidence sinkhole increasing its size. Subsidence phenomena persist in the early sinkhole but also undergo horizontal propagation through the development of collapses in its marginal areas. This evolution has been attested by means of a wide and complete repertory of aerial photographs that have been compared with detailed field and geophysical surveys. Geophysical signatures were used to characterize each evolutionary stage in order to model and evaluate karst hazards related to the identified indicators. This comparison permits the identification of the limits and resolutions of the applied methods and to evaluate the representativeness of the different approaches. Interpretation of their meaning, especially regarding hazard evaluation, requires considering the representativeness and origin of the identified anomalies and their correlation with karst hazards. Special care must be taken when partial approaches are applied without the consideration of the evolutionary model of karst phenomena, in this case, a mantled karst with a thin alluvial cover (less than $10 \mathrm{~m}$ in general), a heterogeneous behavior of the alluvial deposits, the presence of a shallow cemented level and with close interactions between natural and anthropogenic processes.

The main conclusion of this evaluation is the identification of the highest hazard zone in the marginal areas of previous karstic features that define a centrifugal hazard evolution, contrasting with the more common centripetal interpretation. This evaluation is of interest to improve sinkhole inventories and hazard zoning, urban planning or even at the construction scale.

\section{ACKNOWLEDGEMENTS}

Authors want to acknowledge the collaboration during different field campaigns to Diego Ansón, Asunción Soriano, Héctor Gil Garbí, and José Luis Simón. We also acknowledge suggestions from Mario Parise, Jo De Waele (as editor) and two anonymous reviewers. This work was financed by Geotransfer Research Group (Aragón Government) and research projects PI 030/08 (Diputación General de Aragón) and GA-LC-026/2009 (Diputación General de Aragón-Caixa).

\section{REFERENCES}

Al-Kouri O., Al-Rawashdeh S., Sadoun B., Sadoun B. \& Pradhan B., 2013 - Geospatial modeling for sinkholes hazard map based on GIS \& RS data. Journal of Geographic Information System, 5 (6): 584-592. https://doi.org/10.4236/jgis.2013.56055

Ayala Carcedo F.J., Rodríguez Ortiz J.M., del Val Melus J., Durán Balsero J., Prieto Alcolea C. \& Rubio Amo J., 1986 - Mapa del karst en España. Escala 1:000.000. Instituto Geológico y Minero de España. Madrid.

Benson R.C. \& Yuhr L., 1993 - Spatial sampling considerations and their applications to characterizing fractured rock and karst system. In: Beck B.F. (Ed.), Applied Karst Geology. Balkema, Rotterdam, p. 99-113. https://doi.org/10.1007/bf00767501
Berardino P., Fornaro G., Lanari R. \& Sansosti E., 2002 - A new algorithm for surface deformation monitoring based on small baseline differential SAR interferograms. IEEE Transactions on Geoscience and Remote Sensing, 40 (11): 2375-2383.

https://doi.org/10.1109/TGRS.2002.803792

Castañeda C., Gutiérrez F., Manunta M. \& Galve J.P., 2009 - DInSAR measurements of ground deformation by sinkholes, mining subsidence and landslides, Ebro River, Spain. Earth Surface Processes and Landforms, 34 (11): 1562-1574.

https://doi.org/10.1002/esp.1848

Castiella Muruzabal J., del Valle de Lersundi J. \& Ramírez del Pozo J., 1977 - Mapa geológico de España escala 1:50.000. Hoja 321 (26-13, Tauste). Instituto Geológico y Minero de España. Madrid.

Cooper A.H., Farrant A.R. \& Price S.J., 2011 - The use of karst geomorphology for planning, hazard avoidance and development in Great Britain. Geomorphology, 134: 118-131.

https://doi.org/10.1016/j.geomorph.2011.06.004

Esnaola J.M., Leyva F., Marqués L., Ramírez del Pozo J., Herranz J.M., Fernández-Gianotti J. \& Martín-Serrano A., 1995 - Mapa geológico de España escala 1:50.000. Hoja 353 (26-14, Pedrola). Instituto Geológico y Minero de España. Madrid.

Frumkin A., Ezersky M., Al-Zoubi A., Akkawi E. \& Abueladas A.R., 2011 - The Dead Sea sinkhole hazard: geophysical assessment of salt dissolution and collapse. Geomorphology, 134 (1-2): 102-117.

https://doi.org/10.1016/j.geomorph.2011.04.023

Galve J.P., Gutiérrez F., Remondo J., Bonachea J., Lucha P. \& Cendrero A., 2009a - Evaluating and comparing methods of sinkhole susceptibility mapping in the Ebro Valley evaporite karst (NE Spain). Geomorphology, 111 (3-4): 160-172. https://doi.org/10.1016/j.geomorph.2009.04.017

Galve J.P., Gutiérrez F., Lucha P., Bonachea J., Remondo J., Cendrero A., Gutiérrez M., Gimeno M.J. Pardo G. \& Sánchez J.A., 2009b - Sinkholes in the salt-bearing evaporite karst of the Ebro River valley upstream of Zaragoza city (NE Spain). Geomorphological mapping and analysis as a basis for risk management. Geomorphology, 108 (3-4): 145-158. https://doi.org/10.1016/j.geomorph.2008.12.018

Gil Marín C., Santos J.A., Marqués L.A., Esnaola J.M., Ramírez del Pozo J., Marín G., Crespo E., FernándezGianotti J. \& Martin Serrano A., 1995 - Mapa geológico de España escala 1:50.000. Hoja 354 (27-14, Alagón). Instituto Geológico y Minero de España. Madrid.

Gutiérrez F., Cooper A.H. \& Johnson K.S., 2008b Identification, prediction and mitigation of sinkhole hazards in evaporite karst areas. Environmental Geology, 53: 1007-1022.

https://doi.org/10.1007/s00254-007-0728-4

Gutiérrez F., Parise M., De Waele J. \& Jourde H., 2014 - A review on natural and human induced geohazards and impacts in karst. Earth Science Reviews, 138: 61-88. https://doi.org/10.1016/j.earscirev.2014.08.002

Hernández A., van den Hurk A., Ramírez J.I., Navarro J.K., Simón J.L., Rodríguez Santisteban R., García Villar A., del Olmo A., Ramírez del Pozo J., Cuenca G., Fernández-Gianotti J. \& Martín Serrano A., 1995 - Mapa geológico de España escala 1:50.000. Hoja 322 (27-13, Remolinos). Instituto Tectonológico GeoMinero de España. Madrid.

Huang H., 2005 - Depth of investigation for small broadband electromagnetic sensors. Geophysics, 70 (6): G135-G142. https://doi.org/10.1190/1.2122412 
Huang H. \& Won I.J., 2000 - Conductivity and susceptibility mapping using broadband electromagnetic sensors. Journal of Environmental and Engineering Geophysics, 5 (4): 31-41.

https://doi.org/10.4133/JEEG5.4.31

Kaufmann G., 2014 - Geophysical mapping of solution and collapse sinkholes. Journal of Applied Geophysics, 111: 271-288.

https://doi.org/10.1016/j.jappgeo.2014.10.011

Lamelas M.T., Marinoni O., Hoppe A. \& de la Riva J., 2008 - Doline probability map using logistic regression and GIS technology in the central Ebro Basin (Spain). Environmental Geology, 54: 963-977. https://doi.org/10.1007/s00254-007-0895-3

Lindsay J.B. \& Creed I.F., 2006 - Distinguishing actual and artefact depressions in digital elevation data. Computer Geosciences, 32 (8): 1192-1204. https://doi.org/10.1016/j.cageo.2005.11.002

Martínez, J.D., Johnson K.S. \& Neal J.T., 1998 Sinkholes in evaporite rocks. American Scientist, 86: $38-51$

https://doi.org/10.1511/1998.1.38

Mochales T., Casas A.M., Pueyo E.L., Pueyo Ó., Román M.T., Pocoví A., Soriano M.A. \& Ansón D. 2008 Detection of undeground cavities by combining gravity, magnetic and ground penetrating radar surveys: a case study from the Zaragoza area, NE Spain. Envirnonmental Geology, 53: 1067-1077. https://doi.org/10.1007/s00254-007-0733-7

Norman J.W. \& Watson I., 1975 - Detection of subsidence conditions by photogeology. Engineering Geology, 9 (4): 359-381.

https://doi.org/10.1016/0013-7952(75)90016-2

Pardo G., Arenas C., González A., Luzón A., Pérez A., Pérez-Rivarés F.G., Vázquez-Urbez M. \& Villena J., 2004 - La Cuenca del Ebro. In: Vera, J.A. (Ed.), Geología de España. Sociedad Geológica de España and Instituto Geológico y Minero de España. Madrid, p. 533-543.

Perrín J., Cartannaz C., Nourym G. \& Vanoudheusden E., 2015 - A multicriteria approach to karst subsidence hazard mapping supported by weights-of-evidence analysis. Engineering Geology, 197: 296-305.

https://doi.org/10.1016/j.enggeo.2015.09.001

Pueyo Anchuela Ó., Casas Sainz A.M., Soriano M.A. \& Pocovi J.A., 2010a - A geophysical survey routine for the detection of doline areas in the surroundings of Zaragoza (NE Spain). Engineering Geology, 114: 382-396. https://doi.org/10.1016/j.enggeo.2010.05.015

Pueyo Anchuela Ó., Casas Sainz A.M., Soriano M.A., Pocoví Juan A., Ipas Lloréns J.F. \& Ansón López D., $2010 \mathrm{~b}$ - Integrated geophysical and building damages study of karst effects in the urban area of Alcala de Ebro, Spain. Zeitschrift für Geomorphologie, 54 (2): 221-236.

https://doi.org/10.1127/0372-8854/2010/0054S2-0012

Pueyo Anchuela Ó., Casas-Sainz A.M., Soriano M.A. \& Pocoví Juan A., 2011a - Geophysical techniques applied to urban planning in complex near surface environments. Examples of Zaragoza, NE Spain. Physics and Chemistry of the Earth, 36: 1211-1227. https://doi.org/10.1016/j.pce.2011.05.010
Pueyo Anchuela Ó., Casas Sainz A.M., Pocoví Juan A. \& Ansón-López D., 2011b - Multidisciplinary approach for urban planning in alluvial karstic zones. Case study from the Central Ebro Basin (Spain). Engineering Geology, 122 (3-4): 222-238. https://doi.org/10.1016/j.enggeo.2011.05.016

Pueyo Anchuela Ó., Casas Sainz A.M., Pocoví Juan A. \& Soriano M.A., 2011c - Applying GPR-amplitude maps and Am-scans as a semi-quantitative approach to the internal structure of sediments. Journal of Applied Geophysics, 75: 151-160. https://doi.org/10.1016/j.jappgeo.2011.07.002

Pueyo Anchuela Ó., Casas Sainz A.M. \& Pocoví Juan A., 2016 - Indirect geophysical characterization of geohazards in mantled karst environments in the Ebro Basin. First Break, 34: 79-86.

Salvany J.M., Garcia-Veigas J. \& Ortí F., 2007 Glauberite-halite association of the Zaragoza Gypsum Formation (Lower Miocene, Ebro Basin, NE Spain). Sedimentology, 54: 443-467. https://doi.org/10.1111/j.1365-3091.2006.00844.x

Salvany J.M., 2009 - Geología del yacimiento glauberitico de Montes de Torrero (Zaragoza). Ed. Universidad de Zaragoza, $80 \mathrm{p}$.

Simón J.L. \& Soriano M.A., 2002 - Actual and potential doline subsidence hazard mapping: case study in the Ebro basin (Spain). In: Bobrowsky P.T. (Ed.), Geoenvironmental mapping: Method, theory and practice. Balkema, Rotterdam, p. 649-666.

Simón J.L., Soriano M.A., Arlegui L. \& Caballero J., 1998 - Estudio de riesgos de hundimientos en el corredor de la Carretera de Logroño. Public report from the Municipality of Zaragoza, p. 59.

http://www.zaragoza.es/contenidos/urbanismo/ pgouz/memoria/anejos/anejo03/anejo032.pdf.

Simón J.L., Soriano M.A., Gracia J. \& Salvador T., 1991 - Dolinas aluviales en las terrazas del Ebro al oeste de Zaragoza: un análisis empírico de los factores de riesgo. Cuaternario y Geomorfología, 5: 139-148.

Soriano A. \& Simón J.L., 1995 - Alluvial dolines in the central Ebro Basin, Spain: a spatial and developmental hazard analysis. Geomorphology, 11: 295-309. https://doi.org/10.1016/0169-555X(94)00066-Z

Thierry P., Prunier-Leparmentier A.M., Lembezat S., Vanoudheusden E. \& Vernouz J.F., 2009 - 3D geological modeling at urban scale and mapping of ground movement susceptibility from gypsum dissolution: The Paris example (France). Engineering Geology, 105: 51-64. https://doi.org/10.1016/j.enggeo.2008.12.010

Waltham T., Bell F \& Culshaw M., 2005 - Sinkholes and subsidence. Karst and cavernous rocks in Engineering and Construction. Springer. Chichester, UK. 382 p.

Wu Q., Deng C. \& Chen Z., 2016 - Automated delineation of karst sinkholes from LiDAR-derived digital elevation models. Geomorphology, 266: 1-10.

https://doi.org/10.1016/j.geomorph.2016.05.006

Yilmaz I., 2007 - GIS based susceptibility mapping of karst depression in gypsum; a case study from Sivas Basin (Turkey). Engineering Geology, 90 (1-2): 89-103. https://doi.org/10.1016/j.enggeo.2006.12.004

Zhou G., Yan H., Chen K. \& Zhang R., 2016 - Spatial analysis for susceptibility of second-time karst sinkholes: A case study of Jili Village in Guangxi, China. Computers \& Geosciences, 89: 144-160. https://doi.org/10.1016/j.cageo.2016.02.001 